\title{
INVESTIMENTOS PRIVADOS EM INFRAESTRUTURA NAS ECONOMIAS EMERGENTES: A IMPORTÂNCIA DO AMBIENTE REGULATÓRIO NA ATRAÇÃO DE INVESTIMENTOS ${ }^{1,2}$
}

Katia Rocha ${ }^{3}$

\section{SINOPSE}

Qual a resposta dos investimentos privados em infraestrutura a uma melhora nos rankings regulatórios do Brasil? Após a crise financeira global de 2008, as características regulatórias e institucionais se tornaram mais relevantes para alocação do capital privado em infraestrutura nas economias emergentes? A partir do banco de dados sobre participação privada em infraestrutura em economias emergentes disponível pelo Banco Mundial, tentamos responder a essas questôes.

Palavras-chave: infraestrutura; investimentos; ambiente regulatório; capital privado.

\section{INTRODUÇÃO}

A infraestrutura insuficiente e inadequada corresponde a uma das principais barreiras ao crescimento e ao desenvolvimento brasileiros. Conjuntamente, o setor público e o privado investiram em infraestrutura 1,86\% do produto interno bruto (PIB) na média anual da última década (2008-2019), como ilustra o gráfico 1. Esse valor é inferior aos próprios custos de depreciação dos ativos, estimados em 2,41\% do PIB, e muito aquém dos níveis anuais de 4,25\% do PIB recomendados pelo Banco Mundial para um crescimento sustentável.

\section{GRÁFICO 1}

Investimentos em infraestrutura no Brasil: público versus privado (2008-2019)

(Em \%)

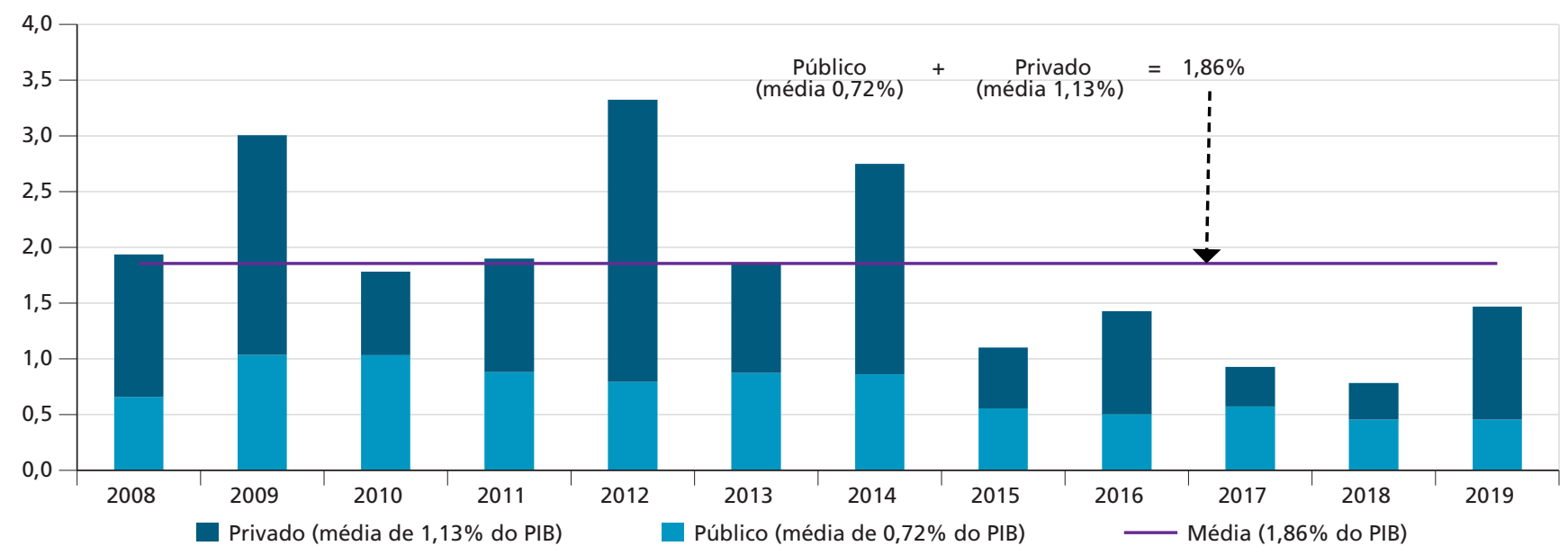

Fonte: Dados da InfraLatam e do World Bank Private Participation in Infrastructure, de 2019. Elaboração da autora.

\section{DOI: http://dx.doi.org/10.38116/radar64art1.}

2. As opiniões emitidas nesta publicação são de exclusiva e inteira responsabilidade do(s) autor(es), não exprimindo, necessariamente, o ponto de vista do Ipea.

3. Técnica de planejamento e pesquisa na Diretoria de Estudos e Políticas Setoriais de Inovação e Infraestrutura (Diset) do Ipea. E-mail: <katia.rocha@ipea.gov.br>. 
Não somente o montante de investimento, mas também a percepção da qualidade do serviço de infraestrutura no Brasil deixam a desejar. De acordo com o pilar de infraestrutura do índice de competitividade global de 2019 - que mede a qualidade, extensão e eficiência da infraestrutura de transporte (rodoviário, ferroviário, aquático e aéreo), além do acesso à energia elétrica e água -, o Brasil se encontra em 78oㅡ em uma amostra de 141 países (na qual Singapura aparece em primeiro lugar).

As incertezas relacionadas à pandemia global do novo coronavírus, as respectivas implicações nas expectativas de depressão econômica e o consequente aumento da aversão ao risco podem limitar ainda mais a oferta de financiamento para projetos de infraestrutura. Portanto, o debate atual recai sobre as recomendaçóes de políticas públicas necessárias para estimular uma maior e melhor participação privada nessa modalidade de investimento. Nesse contexto, a melhoria das características institucionais e regulatórias que promovam os investimentos privados em infraestrutura será particularmente importante ao Brasil nos próximos anos.

Diante dessas questóes, este artigo analisa a relação entre a qualidade regulatória e os investimentos privados em infraestrutura nos países emergentes, explorando os resultados para o Brasil.

\section{METODOLOGIA E RESULTADOS}

A partir de dados de investimentos privados em infraestrutura disponibilizados pelo Banco Mundial no período entre 2000 e 2018, estimamos, por meio de um modelo de painel de efeito fixo, a relação entre qualidade regulatória e investimentos em dezoito economias emergentes - Argentina, Brasil, China, Chile, Colômbia, Índia, Indonésia, Malásia, México, Paquistão, Peru, Filipinas, Rússia, África do Sul, Tailândia, Turquia, Uruguai e Vietnam. Tais emergentes foram responsáveis por cerca de $89 \%$ do fluxo de investimento privado no setor com US\$ 1,3 trilhão de investimentos e 4.480 projetos de infraestrutura.

O indicador de qualidade regulatória, disponível na base de dados do Banco Mundial para mais de duzentos países desde 1998, foi utilizado para medir a percepção institucional do arcabouço regulatório propício a investimentos privados em infraestrutura nos emergentes. $\mathrm{O}$ modelo proposto apresentou resultados significativos e com o sinal esperado, mesmo a partir de uma amostra heterogênea de países, e controlando-se para diversos fundamentos locais e globais. Os resultados indicam que quanto melhor a posição de um país no ranking de qualidade regulatória maiores tendem a ser o volume de investimentos e o número de projetos com participação privada em infraestrutura.

Outro achado interessante diz respeito à quebra estrutural após a crise financeira de 2008. O modelo apontou que, após a crise global, houve aumento significativo da importância da qualidade regulatória do país para a tomada de decisão e alocação do capital privado em infraestrutura nos emergentes.

De forma a contextualizar os resultados, caso o Brasil melhore sua posição no ranking de qualidade regulatória para o mesmo nível ocupado em meados de 2000 ( $65^{\mathrm{a}}$ colocação), teríamos um investimento adicional da ordem de $0,81 \%$ do PIB. Caso alcance os níveis chilenos ( $89^{a}$ colocação), o acréscimo seria de cerca de 1,59\% do PIB. Tal valor somado aos níveis atuais de investimento totalizaria 3,43\% do PIB, valor mais próximo ao alvo de 4,25\% recomendado pelo Banco Mundial. 


\section{CONCLUSÕES}

As estimativas do modelo sugerem que melhorias no ambiente regulatório do Brasil induzem a um aumento potencial da participação privada em infraestrutura de até 1,59\% do PIB anual, o que, somado aos níveis de investimento atuais (público e privado), totaliza cerca de 3,5\% do PIB ao ano. Os resultados são robustos em diversas especificaçôes e características institucionais adicionadas ao modelo e servem de balizadores para toda uma agenda de políticas públicas atualmente em debate no Brasil, que abrange maior abertura econômica, desburocratização, maior segurança jurídica, estabilidade regulatória, fortalecimento da interação entre o Estado e a iniciativa privada por meio de contratos de parceria e de outras medidas de desestatização. Tais aspectos foram de certo modo incorporados na legislaçáo do novo marco regulatório das concessóes e das parcerias públicoprivadas (PPPs) - Projeto de Lei no 7.063/2017, que caminha em direção a uma maior e melhor participação privada em infraestrutura, eficiência dos investimentos públicos e privados em concessóes e PPPs, aproximando o Brasil das melhores práticas internacionais.

\section{REFERÊNCIAS}

RAISER, M. et al. Back to planning: how to close Brazil's infrastructure gap in times of austerity. World Bank, 2017.

ROCHA, K. Investimentos privados em infraestrutura nas economias emergentes: a importância do ambiente regulatório na atração de investimentos. Rio de Janeiro: Ipea, ago. 2020. (Texto para Discussão, n. 2584). 